\title{
Catastrophic rugby injuries of the spinal cord: changing patterns of injury
}

\author{
A. T. Scher MB ChB, DMRD \\ Department of Radiology, Tygerberg Hospital and University of Stellenbosch, Tygerberg, Republic of South \\ Africa
}

\begin{abstract}
In reports from the UK and New Zealand, it is noted that the incidence of rugby injuries to the cervical spinal cord has dropped and that the percentage of players injured in the tackle has similarly decreased. In contrast, this does not appear to be the pattern in South Africa and an analysis has therefore been made of 40 rugby players sustaining injuries to the spinal cord during the period 1985 to 1989 . The radiological appearances on admission have been correlated with the circumstances of injury, associated orthopaedic injuries and neurological deficits. The tackle was responsible for the majority of injuries, causing more than the scrum. Tackles were also responsible for more cases of complete, permanent quadriplegia than the scrum. The commonest cause of injury in players being tackled was the high tackle around the neck, while the commonest cause of injury in players making the tackle was the dive tackle. This survey has shown that the tackle is now the major cause of spinal cord injury in South African rugby, in contrast to earlier analyses in which the scrum was identified as the most common cause.
\end{abstract}

Keywords: Spinal cord injuries, quadriplegia, spinal fractures

In two earlier analyses ${ }^{1,2}$ of rugby injuries to the cervical spinal cord in South Africa and the UK it was noted that the percentage of injuries sustained in the tackle had increased. Recently, Silver $^{3}$ has analysed rugby injuries to the cervical cord in the UK during the 5-year period 1983 to 1987 . He found that there had been an overall reduction in number of injuries sustained and also that the percentage of players injured in the tackle had decreased.

From reports in the media, it would appear that these gratifying improvements are not taking place in South Africa. An analysis of cervical cord injuries in rugby players admitted to the Conradie Hospital in Cape Town during the past 5 years (1985-89) has been made in order to assess the true incidence of injury and to detect any change in the patterns of injury.

Address for correspondence: A.T. Scher, Department of Radiology, Tygerberg Hospital and University of Stellenbosch, PO Box 63, Tygerberg 7505, Republic of South Africa

(C) 1991 Butterworth-Heinemann Ltd.

0306-3674/91/010057-04

\section{Methods and materials}

The case histories and radiographs of all patients admitted during the period 1985-89 with spinal cord injury due to rugby have been analysed. Specific attention has been paid to the circumstances of injury, orthopaedic injuries shown on the radiographs and the neurological deficit present on clinical examination. The cases were subdivided into groups according to the phase of the game during which the injuries were sustained. These cases were further subdivided into groups using the admission radiographs of the cervical spine as indicators of the mechanism of injury.

\section{Results}

A total of 40 rugby players with cervical cord injury. either complete or incomplete, were admitted to the Conradie Hospital Spinal Cord Injury Centre during the period 1985-89. This Spinal Cord Injury Centre is the only such centre in the Cape Province, which is the largest of the four provinces of South Africa with a population of approximately 10 million and an area of 694000 square kilometres. All patients in the Cape Province sustaining spinal cord injury of any description are admitted to this unit.

\section{Age of patients}

The age distribution ranged from 14 to 40 years. Twelve $(30 \%)$ of the players were 17 years of age or under at the time of injury.

\section{Orthopaedic levels of injury}

All the injuries sustained involved the lower cervical spine from $C 5$ to $C 7$. The majority of the injuries were at the C4-5 and C5-6 levels.

\section{Phases of the game in which injury occurred (Table 1)}

The majority of injuries were sustained due to the tackle -20 players $(50 \%)$. Eight players were injured while attempting to make a tackle and 12 players while being tackled. Sixteen players (40\%) were injured in the scrum. 
Table 1. Phases of the game in which injury occurred

\begin{tabular}{|c|c|c|}
\hline & $n$ & $\%$ \\
\hline Scrums & 16 & 40 \\
\hline $\begin{aligned} \text { Tackles: (a) Tackler } \\
\text { (b) Tackled }\end{aligned}$ & $\begin{array}{r}8 \\
12\end{array}$ & 50 \\
\hline Rucks/mauls & 1 & 2.5 \\
\hline Collision & 1 & 2.5 \\
\hline Unknown & 2 & 5 \\
\hline
\end{tabular}

Table 2. Degree of paralysis due to injury in different phases of the game

\begin{tabular}{lcc}
\hline & Incomplete & Complete \\
\hline Scrum & 10 & 6 \\
Tackle & 9 & 11 \\
Ruck & 1 & - \\
Unknown & 1 & 1 \\
Collision & - & 1 \\
\hline
\end{tabular}

Degree of paralysis due to injury in different phases of the game

As can be seen in Table $252.5 \%$ of players sustained incomplete paralysis and $47.5 \%$ complete paralysis. In the group that sustained complete permanent quadriplegia, the majority sustained their injuries in the tackle.

Type of orthopaedic injuries sustained in different phases of the game (Table 3)

Reference to the table shows that there is a wide spectrum of orthopaedic injuries. The majority of scrum injuries were facet dislocations. Amongst the tackle injuries, facet dislocations were also common, as were 'tear drop' fractures (see below).

\section{Mechanism of injury as reflected on admission radiographs}

All those players who sustained orthopaedic injury, had admission radiographs showing flexion injuries or flexion in combination with rotational force or axial compression.

\section{Discussion}

\section{Scrum injuries}

Of the 16 patients injured in the scrum, all were injured due to collapse of the scrum and all were in the front row of the scrum, either props or hookers. Analysis of the orthopaedic injuries revealed that they were all either pure flexion injures or due to flexion with rotation; eight were bilateral or unilateral facet dislocations. These findings are in keeping with all previous analyses of scrum injuries ${ }^{2,4}$ to the cervical spine.

\section{Tackle injuries}

Twenty players were injured in a tackle. Injuries were sustained both by the tackler, because of incorrect technique, and the tackled players, as a result of the force of the tackle and the severity of impact on being forced to the ground. The tackle is not only a common cause for cervical cord injury, but also for injuries in general. Wessels ${ }^{5}$ found that $55 \%$ of rugby injuries were the result of tackles.

Twelve players were injured while being tackled, the commonest cause of injury being the high tackle. The mechanism of injury in the high tackle has previously been described ${ }^{6}$. All players sustained flexion or flexion-rotation injuries with bilateral or unilateral facet dislocation (Figure 1). This is in keeping with a previous analysis of the mechanism of injury when players are tackled high and from the side, the tackler wrapping one arm around the neck and forcing it into hyperflexion. Rotational force is also applied to the neck in this type of tackle. It is the rotational stress applied to the cervical spine during the high tackle that makes this type of tackling so dangerous. If the spine is held in slight flexion and a rotational force applied, the posterior ligaments, joint capsules and posterior longitudinal ligaments will tear, resulting in vertebral dislocation.

Eight players were injured while attempting to make a tackle, the commonest cause of injury being the dive tackle. The mechanism of injury of the dive tackle has also been previously described ${ }^{6}$. The player having launched himself through the air to make a tackle, is brought to a halt abruptly when his head strikes either the ground (after missing his opponent) or the tackled player's thigh. When the neck is slightly flexed, as in the diving position, normal lordosis is lost and the spine straightened. If severe force is applied to the top of the head with the cervical spine in a straight alignment, this force is

Table 3. Type of orthopaedic injury sustained in different phases of the game

\begin{tabular}{|c|c|c|c|c|c|c|c|}
\hline & $\begin{array}{c}\text { Bilateral facet } \\
\text { dislocation }\end{array}$ & $\begin{array}{l}\text { Unilateral facet } \\
\text { dislocation }\end{array}$ & Subluxation & $\begin{array}{l}\text { 'Tear-drop' } \\
\text { fracture }\end{array}$ & $\begin{array}{c}\text { Compression } \\
\text { fracture }\end{array}$ & $\begin{array}{l}\text { Hangman's } \\
\text { fracture }\end{array}$ & $\begin{array}{c}\text { No orthopaedic } \\
\text { injury }\end{array}$ \\
\hline Scrum & 4 & 4 & 2 & - & - & - & 6 \\
\hline Tackle & 3 & 7 & - & 5 & 2 & 2 & 1 \\
\hline Ruck & 1 & - & - & - & - & - & - \\
\hline Unknown & - & 1 & - & 1 & - & - & - \\
\hline Collision & - & - & - & - & 1 & - & - \\
\hline
\end{tabular}




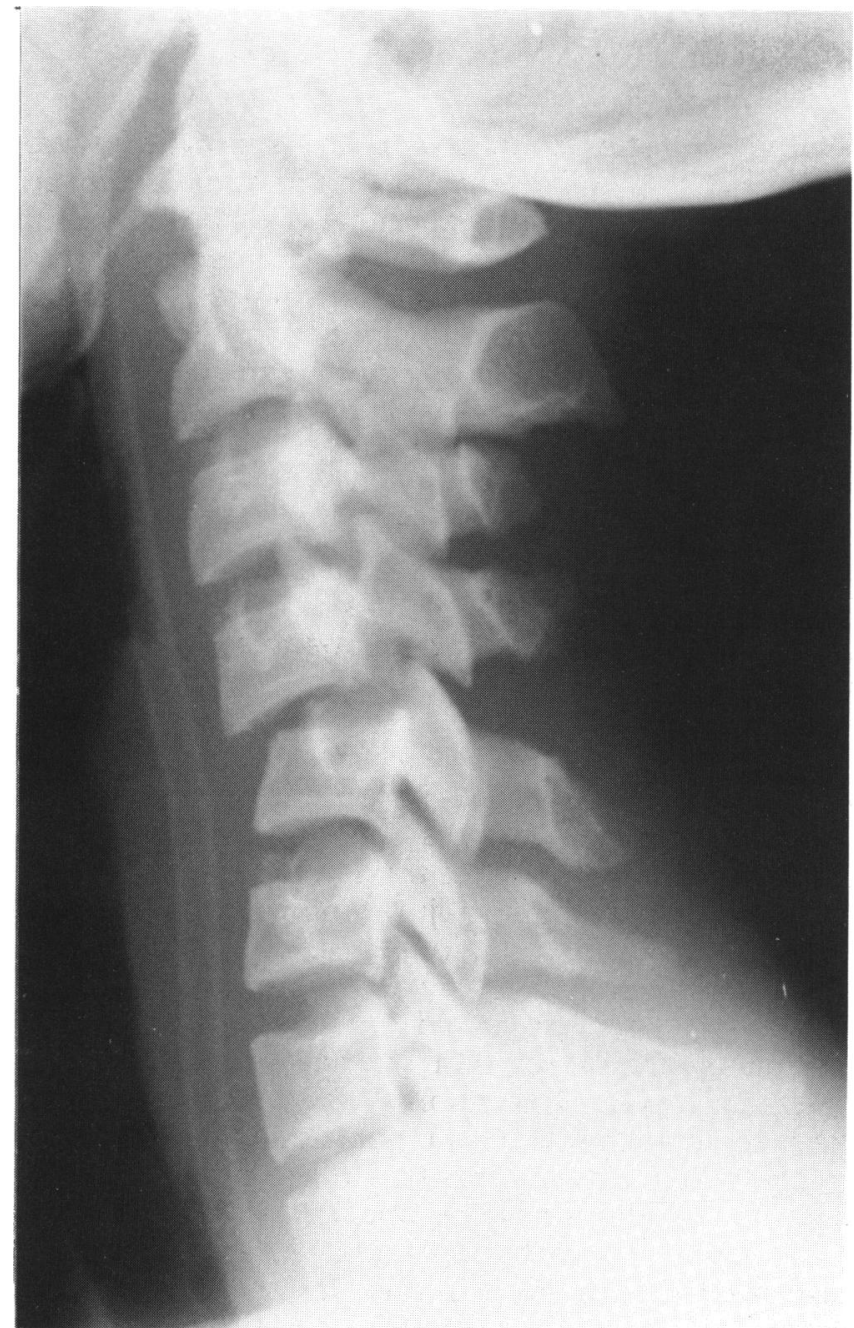

Figure 1. Unilateral facet dislocation at the C4-5 level sustained during a high tackle

transmitted down the long axis of the spine, causing compression fractures of the vertebral bodies. Studies on American football players ${ }^{7}$ have shown that there is a high risk of serious trauma if the head is the primary point of contact on impact.

Not only has the percentage of players injured in the tackle increased, but the number of players sustaining complete paralysis due to the tackle has also increased disproportionately, compared to previous surveys $1,2,4$. Whereas previous reports have identified the scrum as the most important cause of permanent quadriplegia, in the present series tackle injuries have been more serious. Eleven of the 20 players involved in the tackle sustained complete quadriplegia.

Analysis of the type of orthopaedic injuries sustained in the tackle explains the high incidence of complete paralysis. The commonest injuries sustained were facet dislocations (Table 3) either bilateral or unilateral. The forward displacement of the superior vertebral body at the level of injury causes

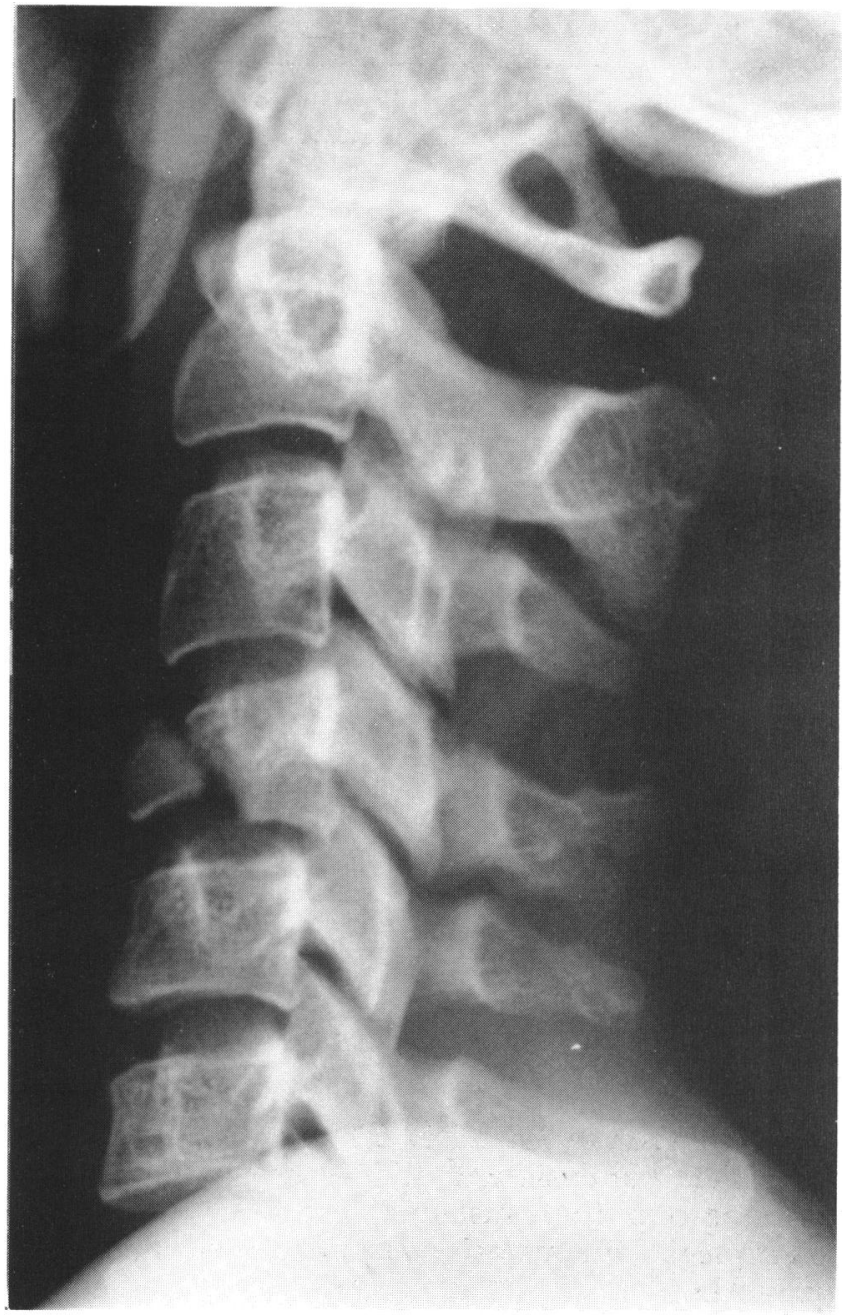

Figure 2. 'Tear drop' fracture of the vertebral body of C4. The vertebral body has been divided into a smaller, triangular, anterior fragment and a larger posterior fragment which has been displaced posteriorly into the spinal canal

severe cord compression and injury. The second commonest orthopaedic injury noted was the flexion 'tear drop' fracture. This fracture derives its name from the characteristic triangular shaped fragment that fractures from the antero-inferior corner of the vertebral body, said to resemble a drop of water dripping from the vertebral body (Figure 2). The posterior fragment of the divided body is displaced backwards into the spinal canal. These fractures, resulting from a combination of forceful flexion and axial compression, are usually associated with very serious neurological damage ${ }^{8}$.

This survey has shown that despite the numerous changes in the laws of rugby, intensive media interest and high level of public awareness, the situation as regards cervical spinal cord injuries in South Africa has not improved in recent years. A previous analysis has also suggested that the situation in South Africa is unsatisfactory ${ }^{2}$. This is in contrast to the UK ${ }^{1}$ and New Zealand ${ }^{9}$ where significant and gratifying decreases in the incidence of injuries have occurred. 
Not only has the incidence of injury remained high, but the pattern of injury have changed, with tackle injuries predominating. This is disturbing as the majority of tackle injuries in this survey were consequent upon either poor technique or deliberate foul play. In contrast, Silver ${ }^{3}$ reported on 63 rugby players with spinal cord injuries in the UK and recorded only two injuries due to the high tackle.

Tackling is an integral part of rugby, and drastic changes in the rules in an endeavour to remove all physical danger are impractical, but certain points obviously need to be emphasized. The technique of safe tackling must be stressed, particularly at junior level. Wildly executed diving tackles, with little chance of reaching the opponent, should be discouraged.

The high tackle is still common practice, and although this is sometimes accidental owing to miscalculation during a fast movement, these tackles are often deliberate. It is clearly stated in the laws of rugby football that 'it is illegal for any player to tackle late or early or dangerously, including the action known as a stiff arm tackle ${ }^{10}$. Rigorous enforcement of this rule is necessary in order to decrease the number of these tragic and avoidable injuries.

\section{References}

1 Silver JR. Injuries of the spine sustained in rugby. $\mathrm{Br}$ Med J 1984; 288: 37-43.

2 Scher AT. Catastrophic rugby injuires of the spinal cord: an increasing problem. SA Sports Med J 1989; 4(1): 11-12.

3 Silver JR, Gill S. Injuries of the spine sustained during rugby. Sports Med 1988; 5: 328-34.

4 Scher AT. Rugby injuries of the spine and spinal cord. Clin Sports Med 1987; 6(1): 87-99.

5 Wessels LGD. Rugby injuries in South Africa. $S$ Afr Sports Med 1980; 8: 14-16.

6 Scher AT. The high rugby tackle: an avoidable cause of cervical spinal injury? S Afr Med J 1978; 53: 1015-18.

7 Torg JS, Vegso JJ, Sennett B, Das M. The National Football Head and Neck Injury Registry; JAMA 1985; 254(24): 3439-43.

8 Schneider RC, Kahn EA. Chronic neurologic sequelae of acute trauma to the spine and spinal cord. J Bone J Surg 1956; 38-A(5): 985-97.

9 Burry HC, Gowland H. Cervical injury in football: a New Zealand survey. Br J Sports Med 1981; 15: 56-60.

10 South African Rugby Board. Laws of the Game of Rugby Football. Cape Town: S.A. Rugby Board, 1988: 54. 